\title{
The Role of Accidental and Therapeutic Hypothermia in Non-Fatal Drowning
}

\author{
Jonathan Gauci, Karen Anne Cassar, Sarah-Ann Mercieca, Jonathan Joslin, Noel Borg \\ Mater Dei Hospital, Malta
}

Doi: 10.12890/2015_000195 - European Journal of Case Reports in Internal Medicine - C EFIM 2015

Received: 26/02/2015

Accepted: 23/03/2015

Published: 09/04/2015

How to cite this article: Gauci J, Cassar K A, Mercieca S A, Joslin J, Borg N. The role of accidental and therapeutic hypothermia in non-fatal drowning. EJCRIM 2015;2:doi: 10.12890/2015_000195

Conflicts of Interests: The authors declare that they have no conflicts of interest in this research

This article is licensed under a Commons Attribution Non-Commercial 4.0 License

\section{ABSTRACT}

A case of non-fatal drowning with a successful outcome despite a submersion time of 25 min is described. Our case report emphasizes the role of accidental hypothermia in the survival of drowning victims with hypoxic brain injury, and supports the use of therapeutic hypothermia in the resuscitation of these patients.

\section{LEARNING POINTS}

- Accidental hypothermia protects against brain injury by shunting oxygenated blood towards the vital organs, and by decreasing the oxygenation needs of tissues.

- Therapeutic hypothermia protects against brain injury by slowing metabolism and by decreasing reperfusion injury.

- Drowning victims with restoration of spontaneous circulation who remain comatose should not be actively re-warmed to temperatures above $32-34^{\circ} \mathrm{C}$.

\section{KEYWORDS}

Non-fatal drowning, hypothermia

\section{CASE PRESENTATION}

A 20-year-old Eastern European man was brought to the emergency department after being rescued from seawater following a motor vehicle accident that occurred in the early hours of a winter morning. The car he was driving broke through a crash barrier and fell into the sea in a yacht marina, and he remained immersed in cold water for around $25 \mathrm{~min}$ before being rescued.

The patient was found to be pulseless on site, and cardiopulmonary resuscitation (CPR) was started immediately. Cardiac monitoring initially showed pulseless electrical activity followed by a period of asystole, and return of spontaneous circulation was obtained after 10 min of CPR. The patient was then hypothermic (rectal temperature $31.1^{\circ} \mathrm{C}$ ), bradycardic $(35 \mathrm{bpm})$ and hypotensive $(89 / 44 \mathrm{mmHg})$, with fixed dilated pupils. Arterial blood gases initially showed severe respiratory acidosis ( $\mathrm{pH} 6.85$ ) with a high lactate of 13.8 . Intravenous atropine was given, followed by an infusion of adrenaline, which led to an improvement in heart rate (112 bpm) and blood pressure (112/42 mmHg). He was left hypothermic at $31.1^{\circ} \mathrm{C}$.

The patient was admitted to the intensive therapy unit (ITU), sedated with propofol and intubated. Intravenous piperacillin-tazobactam was started since the patient had aspirated a large amount of murky seawater. Laboratory investigations revealed neutrophilia, hypernatraemia and normal coagulation. Computed tomography showed generalized brain oedema and bilateral dependent lung consolidations. His vital parameters remained stable, the acidosis improved and his body temperature rose spontaneously (Fig. 1).

On his second day in the ITU, the patient was noted to have episodes of limb jerking for which intravenous phenytoin was started. On day 5 , sedation was stopped and the patient opened his eyes spontaneously and obeyed simple commands. The next day he was transferred to a medical ward, where he improved gradually, with no further seizures on oral phenytoin. An electroencephalogram and magnetic resonance imaging of the brain were normal.

On the medical ward, he started verbalising appropriately at times. However, he was noted to be intermittently agitated and delusional, stating that his friends from abroad had come to see him while he was in intensive care. He was apathetic and needed to be coaxed to get out of bed and to eat. He acknowledged a lack of appetite that resulted in his refusal to eat. Psychiatric review confirmed that he demonstrated clear signs of frontal and executive impairment with poor awareness of social cues and lack of appropriate inhibition. These features were most likely due to the prolonged hypoxia during the near-drowning episode and were not pre-existing. He was started on oral risperidone with good effect, and this was tapered down and stopped when his behaviour became more appropriate.

After a 5-week period of inpatient rehabilitation, the patient's verbalization and behaviour had improved remarkably and he was discharged home on oral phenytoin, with close neurology and psychiatric follow-up. 


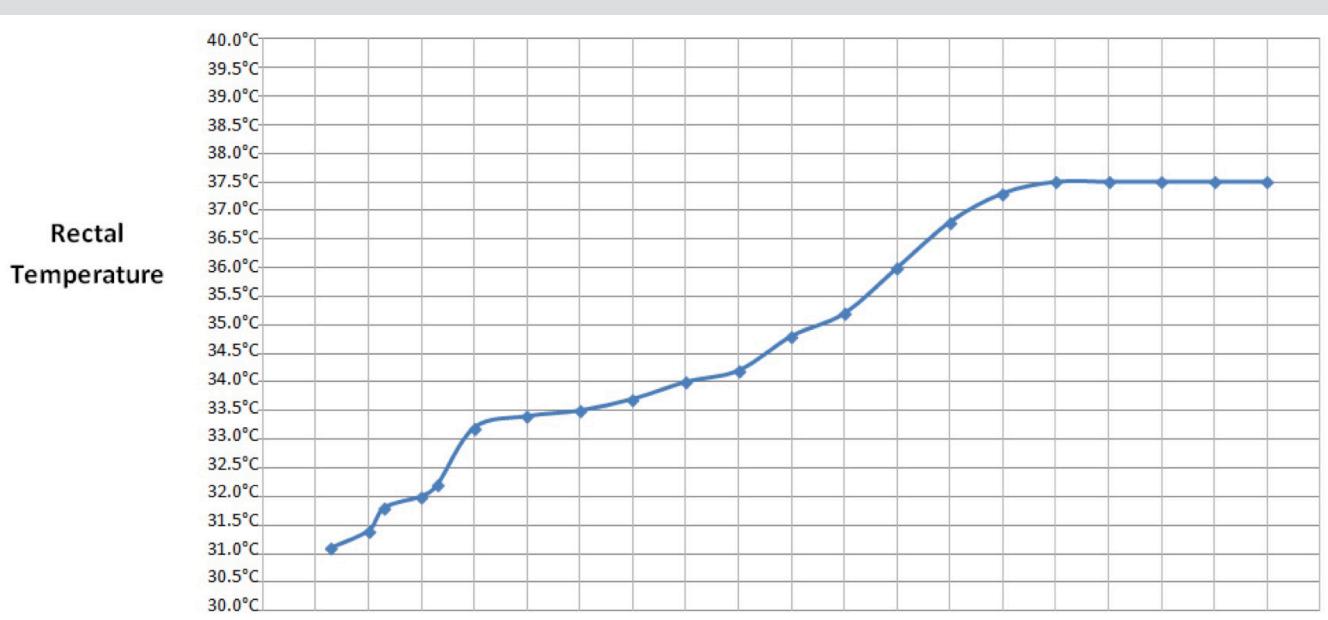

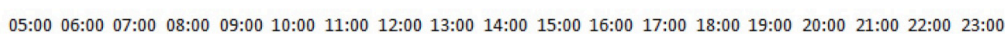

Time - Day 1 in ITU
Figure 1: Rectal temperature on day 1 in the intensive therapy unit

\section{DISCUSSION}

\section{Accidental hypothermia}

The factors that increase the chance of surviving submersion without permanent morbidity were traditionally thought to be the following ${ }^{[1]}$ :

- rapid institution of resuscitation

- brief submersion duration

- cold water temperature (accidental hypothermia)

- young age

- absence of underlying medical conditions, secondary trauma, and aspiration of particulate matter or chemicals.

Rapid institution of resuscitation is essential to ensure survival in drowning victims, and this includes both speed of rescue and early initiation of effective CPR. There is some debate regarding the temperature and age factors. Submersion in icy water leads to accidental hypothermia and may provide some protection against hypoxia. Hypothermia stimulates the mammalian diving reflex, slowing the heart rate, and constricting the peripheral arteries, thus shunting oxygenated blood away from the extremities and the gut towards the heart and brain, particularly in young children ${ }^{[1]}$. Also, hypothermia decreases the oxygenation needs of tissues, possibly prolonging survival and delaying the onset of hypoxic tissue damage ${ }^{[1]}$. Retrospective reviews have shown that the sudden onset of hypothermia increases the time one can be submerged and still make a full neurological recovery after rescue ${ }^{[2]}$.

On the other hand, several studies have demonstrated that the beneficial effects of accidental hypothermia due to icy water could not be proven. Rather, it was shown that submersion time is the best prognostic factor after a non-fatal drowning incident, when compared to patient age, water temperature and rectal temperature in the emergency room, which were not significant predictors of survival[3]. Submersions for greater than $10 \mathrm{~min}$ were associated with a poor prognosis ${ }^{[4]}$. The victim in our case report was submerged for 25 min prior to rescue with a successful outcome, and we suggest that accidental hypothermia may have had an important role in leading to neurological recovery.

\section{Therapeutic hypothermia}

The optimal rewarming strategy is unclear, as there may be benefits from leaving the patient hypothermic. Therapeutic hypothermia protects the vital organs by slowing metabolism by $6 \%$ for every $1{ }^{\circ} \mathrm{C}$ decrease in core body temperature, and also significantly decreases reperfusion injury ${ }^{[5]}$. It results in a reduction in cerebral metabolic demands, a reduction in intracranial pressure, and halts the apoptosis pathway in the post-ischaemic cells ${ }^{[5]}$.

The induction of therapeutic hypothermia in post-hypoxic coma following cardiac arrest due to ventricular fibrillation has been shown to reduce mortality and improve neurological outcome. Therapeutic hypothermia in hypoxic brain injury after non-fatal drowning is less studied, but there have been a number of case reports. Williamson et al. described a victim with severe acidosis, hyperlactaemia and a low Glasgow Coma Scale (GCS) score with fixed dilated pupils who had a successful outcome after therapeutic hypothermia, as in our case report ${ }^{[6]}$.

The European Resuscitation Council maintains that there is no convincing evidence to guide therapy in drowning patients, but quotes the International Life Saving Federation, which recommends that drowning victims with restoration of adequate spontaneous circulation who remain comatose should not be actively re-warmed to temperature values above $32-34^{\circ} \mathrm{C}$. One should consider rewarming severely hypothermic patients until a core temperature of $32-34^{\circ} \mathrm{C}$ is achieved. If core temperature exceeds $34^{\circ} \mathrm{C}$, hypothermia $\left(32-34^{\circ} \mathrm{C}\right)$ should be instituted as soon as possible and sustained for 12-24 $h^{[7]}$. Intravenous CPR drugs are less effective and should be withheld in severe hypothermia until the core temperature exceeds $30^{\circ} \mathrm{C}$ [7]. 


\section{REFERENCES}

1. Merck Sharp \& Dohme Corp. The Merck Manual - Drowning. 2013 [cited 1 Feb 2015]. Available from: http://www.merckmanuals.com/professional/injuries poisoning/drowning/drowning.html Clemens T. Non-fatal drowning: a review of epidemiology, pathophysiology, treatment and prevention. 2013 [cited 1 Feb 2015].

Available from: http://www.wcdp2013.org/uploads/media/Research6_1_255_Non_fatal_drowning_TessaClemens.pdf

Suominen P, Baillie C, Korpela R, Rautanen S, Ranta S, Olkkola KT. Impact of age, submersion time and water temperature on outcome in near-drowning. Resuscitation 2002;52:247-254.

DeNicola LK, Falk JL, Swanson ME, Gayle MO, Kissoon N. Submersion injuries in children and adults. Crit Care Clin 1997;13:477-502.

International Liaison Committee on Resuscitation (ILCOR). Advisory statement: therapeutic hypothermia after cardiac arrest. Circulation 2003;108:118-121.

Williamson JP, Illing R, Gertler P, Braude S. Near-drowning treated with therapeutic hypothermia. Med J Aust 2004;181:500-501.

7. European Resuscitation Council. Guidelines for Resuscitation 2010 Section 8: Cardiac arrest in special circumstances. 2010 [Accessed 1 Feb 2015]

Available from: http://resuscitation-guidelines.articleinmotion.com/article/S0300-9572(10)00441-7/fulltext\#aff0020 